\title{
PCK do Licenciado em Computação: Especificidades Pedagógicas da Docência em Computação
}

\author{
Lilian Pereira da Silva Teixeira ${ }^{1}$ \\ ${ }^{1}$ Instituto Federal de Educação, Ciência e Tecnologia Baiano (IF Baiano) - Senhor do \\ Bonfim - BA - Brasil \\ Lilian.teixeira@ifbaiano.edu.br
}

\begin{abstract}
In this study, the seven main attributes that make up the Pedagogical Content Knowledge of the computer teacher are presented. The discussion of this article is part of the results of a doctoral thesis developed from the mixed methodological approach (qualitative/quantitative). The public participating in the research comprises 60 graduates of the degree in computing from institutions in the five regions of Brazil. It is concluded that computing teachers demonstrate that their Pedagogical Content Knowledge base for teaching computing is guided by the following attributes: autonomy, didactic transposition, contextualization, computational thinking/reasoning, mediation, interdisciplinarity, and planning.
\end{abstract}

Resumo. Apresenta-se nesse estudo, os sete principais atributos que compõem o Conhecimento de Conteúdo Pedagógico do professor de computação. A discussão desse artigo é parte dos resultados de uma tese de doutorado desenvolvida a partir da abordagem metodológica mista (quali/quanti) e da análise de conteúdo. $O$ público participante da pesquisa compreende 60 egressos da licenciatura em computação de instituições das cinco regiões do Brasil. Conclui-se que os professores de Computação demonstram que sua base de Conhecimento de Conteúdo Pedagógico para o ensino de Computação é orientada pelos seguintes atributos: autonomia, transposição didática, contextualização, pensamento/raciocínio computacional, mediação, interdisciplinaridade, e planejamento.

\section{Introdução}

A criação da Licenciatura em Computação (LC) no Brasil apresenta-se como uma das respostas à necessidade de se contemplar dentre os cursos de formação de professores uma Licenciatura que apresente uma formação docente voltada às tecnologias digitais de informação e comunicação, propondo mediação pedagógica e transposição didática específicas. Trata-se de um curso que pode promover uma formação que relaciona reflexivamente as mídias, a tecnologia e a educação numa perspectiva crítica, produtiva e criadora.

Estudos realizados recentemente em vários países revelam que há grande probabilidade de que a área de Computação ou Informática venha a tornar-se um componente curricular regular na Educação Básica, assim o Pedagogical Content Knowledge (PCK), ou seja o Conhecimento de Conteúdo Pedagógico, é um elemento 
importantíssimo que pode subsidiar um processo de análise acerca do pensamento do professor que ensina Computação. Porém, é necessário situar as compreensões atuais sobre esse ensino, principalmente na Educação Básica bem como compreender o que pensam os próprios docentes da área da computação sobre os principais atributos pedagógicos que estão mais presentes em sua prática.

\section{Pedagogical Content Knowledge (PCK) no Contexto do Conhecimento Tecnológico}

O termo Pedagogical Content Knowledge (PCK), foi inicialmente apresentado por Lee Shulman (1986; 2014), durante o movimento reformista que aconteceu no Canadá e nos Estados Unidos, na segunda metade da década de 1980, em que reivindicava-se o status profissional para os profissionais da educação [Marcon, 2013]. Shulman (1986) defende em sua proposta que os professores são detentores de um conhecimento especializado do conteúdo. Esse estudo teve um grande impacto, originando um campo específico de investigação que focaliza o "conhecimento específico do professor".

$\mathrm{O}$ autor argumenta que os estudos sobre o conhecimento do professor na maioria das vezes apresentam o seu foco nos aspectos pedagógicos da gestão da aula, porém ignora-se que há também um aspecto interessante a ser observado o conteúdo disciplinar do professor, denominado por "subject matter". Esse conteúdo altamente personalizado e envolvido de autoria e subjetividade seria uma análise referente ao produto da transposição do conteúdo disciplinar que transforma-se no momento do ensino, referese ao produto desse conteúdo, que passa por transformações no momento em que é ensinado por cada professor.

De acordo com Mishra e Koehler (2006), pode-se representar a contribuição de Shulman de forma ilustrativa conectando duas circunferências, de modo que sua interseção represente o $P C K$ como interação entre o conhecimento disciplinar e o conhecimento pedagógico, através das contextualizações das estratégias pedagógicas utilizadas no exercício do ensino

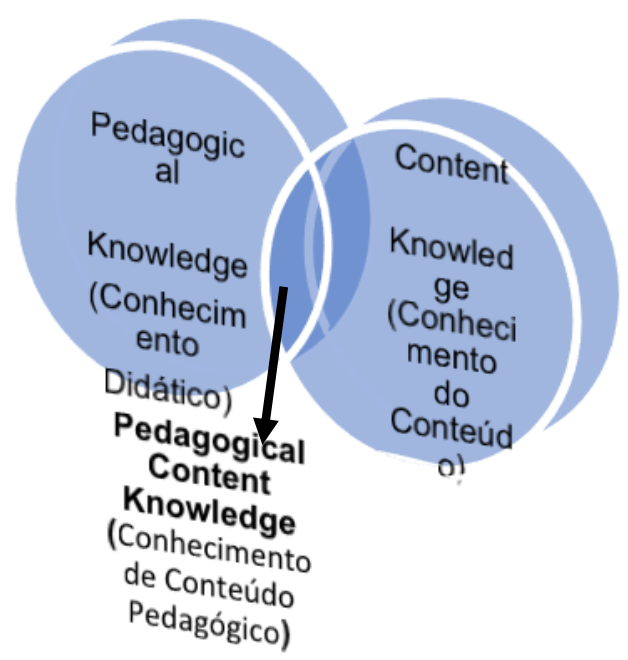


Esse modelo indica que, na tentativa de desenvolver um trabalho exitoso em sala de aula, os professores pensam sobre as questões do conteúdo específico da disciplina e sobre as formas pedagógicas aplicáveis, ou seja, pensam a melhor forma de tornar o conteúdo compreensível pelos alunos. A interseção acima expressa a produção do conhecimento do professor no sentido de incorporar a sua aula os aspectos do conteúdo mais pertinentes à sua capacidade de ensino. No "coração" do $P C K$ está a maneira pela qual o conteúdo da disciplina é transformado para o ensino [Mishra; Koehler, 2006].

\section{PCK: a sabedoria que se origina da própria prática no ensino de Computação}

As representações dos professores sobre o Conhecimento de Conteúdo Pedagógico da sua prática são traduzidas de diferentes formas, conforme Shulman (2014), "se traduzem em jeitos de falar, mostrar, interpretar ou representar ideias" (p. 205). A sabedoria da prática é uma das fontes da base do conhecimento sobre o ensino que o professor adquire no seu cotidiano.

A seguir, apresenta-se 7 (sete) atributos do $P C K$ dos professores de computação que se originaram de uma pesquisa de tese de doutorado. A perspectiva de análise de análise utilizada que possibilitou o resultado a ser apresentado foi a análise de conteúdo de Lourence Bardin (2016) na dimensão qualitativa da pesquisa, através da qual foram colhidas narrativas orais através de entrevistas semiestruturadas com 11 (onze) professores de computação que são egressos da Licenciatura em Computação que estão distribuídos nas cinco regiões do Brasil.

Para análise de conteúdo dos dados qualitativos das narrativas das entrevistas, foi utilizado como ferramenta de apoio o software Maxqda. Optou-se pelo uso do software Maxqda por ser um software de auxílio à análise qualitativa cujas ferramentas se mostram coerentes com a perspectiva de Análise de Conteúdo.

\section{Atributos do PCK dos professores de Computação}

Afirma-se que o $P C K$ em ação pode ser compreendido pela mistura complexa daquilo que o professor sabe (em termos de conteúdos disciplinares e curriculares) com aquilo que o professor faz (saberes da experiência e da ação), ou seja, com aquilo que ele desenvolve na prática com os seus alunos [Bouchard, 2013].

Dessa forma, o professor constrói categorias/atributos que se tornam referenciais para si próprio de como ministrar uma boa aula, de como facilitar a aprendizagem dos seus alunos e, em alguns momentos, de como se dá uma combinação de atributos pedagógicos que fundamentam o $P C K$.

Adiante, lista-se, através de uma breve análise, os 7 (sete) atributos do $P C K$ dos professores de Computação indicados a partir análise de dados qualitativos desta pesquisa. 


\subsection{Autonomia}

O desenvolvimento da autonomia é uma categoria intrínseca ao ensino de Computação que é desenvolvido de forma construtiva e contextualizada. Quando o ensino de Computação é desenvolvido para além das noções tradicionais dos conhecimentos de informática e Computação, de forma que os sujeitos aprendentes consigam aplicá-las produtivamente em suas vidas cotidianas, então, se diz que essa formação é baseada na noção de Fluência da Tecnologia da Informação (FITness) [Harris; Mishra; Koehler, 2009], ou ainda pode-se afirmar que o sujeito está a desenvolver a Digital Wisdom [Prensky, 2011], ambos os conceitos nascem da perspectiva do desenvolvimento da autonomia.

Nas narrativas dos egressos, o termo "autonomia" é indicado como um elemento muito presente na orientação e condução do ensino de Computação, assim como trata-se de uma habilidade desenvolvida no percurso de aprendizagem, pois compreende-se que o ensino de Computação pode proporcionar aos sujeitos habilidades no uso de tecnologias que os tornarão autores, ou ainda avaliadores críticos e não meros consumidores de produtos tecnológicos e digitais.

"É a era da informação, da autoria, então os alunos são autores do seu próprio aprendizado. Eles buscam, enfrentam as possibilidades, vão atrás e tentam aprender" (Sul 01).

[...] porque o conteúdo de Computação, ele permite que o professor não somente ensine coisas do tipo, aprender a ligar e desligar um computador, mas que o aluno aprenda por ele mesmo a fazer as coisas. A fazer as coisas dele, criar autonomia, eu acho que você deve criar autonomia para o aluno pra que ele não seja só um consumidor de tecnologia, que aprenda a produzir (Nordeste 01).

Os fragmentos das narrativas dos entrevistados Nordeste 01, Nordeste 04 e Sul 02, corroboram o pensamento de Trocmé-Fabre (2004), no sentido de conceber a "autonomia" como construção ao longo do processo de aprendizagem que ocorre de forma colaborativa, no coletivo, mas que também compõe um processo individual e subjetivo do sujeito.

A autonomia como construção, como algo pessoal, de cada um, subjetivo, mas desenvolvido na coletividade, na interatividade, na colaboração, como percurso requer a participação do outro, sobretudo dos educadores para que seja experimentada ampliada, construída ao longo de toda a vida [Trocmé-Fabre, 2004, p. 33].

Prensky (2012) reflete afirmando que está ao dispor da população máquinas e softwares cada vez mais poderosos, mas, para que essas máquinas trabalhem em favor do homem de forma ética, inclusiva e potencializadora da atividade humana, é necessário que desde a pré-escola os estudantes aprendam os princípios de Computação, da Programação. Prensky (2012) sugere que aprender a programar deveria ser uma das habilidades mais importantes a ser desenvolvida pelos estudantes da Educação Básica.

Assim, os egressos revelam que a autonomia é conquistada através do domínio de tais habilidades, o que vem a ser um dos atributos que compõem o seu Conhecimento de Conteúdo Pedagógico do ensino de Computação. 


\subsection{Transposição Didática}

Há no posicionamento dos egressos que atuam no ensino de Computação um forte indicativo de que esses concebem a necessidade de um esforço maior no exercício da atividade docente, para que ocorra o que se chama de transposição didática no ensino de Computação.

Mas, o que é transposição didática?

De acordo com Chevallard (1998), o termo transposição didática foi empregado inicialmente pelo sociólogo francês Michel Verret em 1975, mas a popularização do termo na área de educação deu-se a partir da divulgação dos estudos de Yves Chevallard, que aprofundou o tema no livro La Transposition Didactique, lançado em 1985.

Denomina-se transposição didática o processo de transformação que ocorre na passagem do saber científico ao saber ensinado, mas nesse processo há também transformações/deformações de um saber que se torna um conhecimento "escolarizado", esse conhecimento assume uma linguagem acessível aos alunos.

Para os egressos da Licenciatura em Computação, há um exercício constante, e com certo grau de dificuldade em se realizar a transposição didática do conhecimento da Computação de modo que este conhecimento torne-se um conteúdo a ser parte de um determinado currículo escolar, pois, por ser uma área recente, a Computação não dispõe de referenciais para o ensino "escolarizado", sobretudo na Educação Básica.

A questão do campo, eu acho que é complicado, porque o que a gente vê na faculdade em termos de conteúdo é muito difícil de se transformar em conteúdo na Educação Básica (Nordeste 02).

[...] Então, você tem que mastigar, como a gente diria, você tem que transpor daquela coisa muito técnica para alguma coisa um pouco mais simplificada, aí você vai fazer relações, vai trocar ideia com o aluno para simplificar aquilo, para ser mais fácil a absorção do conhecimento, do conteúdo (Sul 03).

O relato da entrevistada Sul 03 revela que a linguagem utilizada em sala de aula para o ensino de Computação não é a mesma aplicada pela ciência e, para que essa linguagem torne-se acessível ao educando, há um esforço didático por parte do professor de Computação, há uma transformação para a produção do saber a ser ensinado, a fim de atender às necessidades do alunado. "El docente en su clase, el que elabora los programas, el que hace los manuales, cada uno en su âmbito, instituyen una norma didáctica que tiende a constituir un objeto de enseñanza como distinto del objeto al que da lugar" [Chevallard, 1998, p. 51-52].

Diante da necessidade constante de transformação do saber computacional a ser ensinado, a "transposição didática" torna-se uma importante categoria do $P C K$ do professor de Computação.

\subsection{Pensamento Computacional}

Entre os países mais desenvolvidos do mundo há um apelo tanto por parte dos órgãos governamentais, quanto por parte das famílias e dos educadores que os estudantes sejam melhor preparados ainda na Educação Básica para as carreiras profissionais que se inserem no mundo digital [Hennessey et al., 2017]. 
Assim, se observa que a inserção na Educação Básica de atividades que exploram o Pensamento/raciocínio Computacional torna-se uma perspectiva de ensino amplamente defendida pelos cientistas da Computação.

Desse modo, pensar computacionalmente é tornar a modelagem dos aspectos relevantes de um problema tratável; é ter a confiança que se pode usar, modificar e influenciar um sistema grande e complexo sem necessariamente entender todos os seus detalhes com segurança; enfim, é usar raciocínio heurístico na descoberta da solução de um problema.

Para Wing (2006), não se deve reduzir a perspectiva ensino de Pensamento Computacional ao o ensino de programação. "Pensar como um cientista da Computação significa mais do que ser capaz de programar um computador. É preciso pensar em múltiplos níveis de abstração.” (p. 34)

Assim, as entrevistas realizadas nesta pesquisa revelam que os professores de Computação brasileiros compreendem a importância desta área de discussão e estão alinhados com os estudos internacionais, voltados à análise da inserção do Pensamento/raciocínio Computacional no currículo escolar desde a Educação Básica.

“O conteúdo ele é mutável a partir do ponto de vista temporal, mas o que é que não morre no meio disso? A abstração e a lógica" (Nordeste 04).

"É importante que o aluno entenda o processo de funcionamento do computador, bem como questões ligadas ao Pensamento Computacional. Acredito que na Educação Básica devem ser trabalhados conteúdos ligados ao Pensamento Computacional (Nordeste 02).'

[...] mas eu penso que o Pensamento Computacional, que está muito em voga na atualidade, porque ele (professor de Computação) também vai atuar nessa área, porque se ele vai atuar na Educação Básica ele vai atuar diretamente com o Pensamento Computacional nas classes de Ensino Fundamental e Médio. [...] é uma necessidade muito pertinente de você utilizar, de você ensinar, de você conhecer os conceitos do Pensamento Computacional para você conseguir desenvolver atividades nesse sentido nas séries de Educação Básica (Sul 01).

A fala do entrevistado Sul 01, sugere que haja um componente curricular no Ensino Fundamental nomeado Pensamento Computacional, esse mesmo posicionamento foi observado na fala de outros entrevistados, como por exemplo Nordeste 02.

Segundo Hennessey et al. (2017), existem dois tipos de abordagem para inserção do Pensamento Computacional no currículo da Educação Básica. Uma abordagem sugere a criação de um componente curricular específico para o trabalho com o Pensamento Computacional. A outra abordagem sugere que a perspectiva do Pensamento Computacional seja inserida em várias áreas do currículo escolar, como, por exemplo, matemática, linguagem, música, etc. "Por exemplo, um grupo de educadores combinou Ciência da Computação com a música, ensinando o código musical ao vivo dos alunos com o programa Scratch do MIT"1 (p. 80).

Conforme Shulman (2014), há uma base de conhecimentos para o ensino que produz o $P C K$ dos professores e nesta base estão os conhecimentos disciplinares, e também conteúdos específicos para ensinar matérias (Computação). Assim, o

\footnotetext{
${ }^{1}$ MIT - Media Lab do Massachusetts Institute of Technology
} 
Pensamento Computacional integra, na condição de conhecimento específico, essa base de conhecimentos e estratégias pedagógicas que estão na mente do professor de Computação.

\subsection{Interdisciplinaridade}

$\mathrm{O}$ aspecto da interdisciplinaridade é muito presente na identidade docente do professor de Computação. Esse aspecto aparece naturalmente entre as categorias do $P C K$ do professor de Computação, pois sua identidade e seu Conhecimento de Conteúdo Pedagógico estão intrinsecamente interligados.

Alguns estudiosos afirmam que estamos na era do pensamento complexo que envolve habilidades interdisciplinares. Estar no mundo do trabalho atualmente exige a habilidade de transitar entre diversos campos do conhecimento e disposição para trabalhar em equipe. "Neste sentido, a área da ciência da Computação e suas diferentes subáreas têm sido pródigas em bons exemplos" [Teixeira\& Bastos, 2016, p. 24].

$\mathrm{Na}$ sequência, tem-se fragmentos de narrativas que indicam a interdisciplinaridade como uma importante categoria do $P C K$ do professor de Computação.

A Computação na sala de aula, na parte pedagógica, eu consigo ter uma estrutura, que perpassa várias disciplinas, então, assim, ela é interdisciplinar. Então, significativo é eu conseguir passar, unir vários conhecimentos e fazer coisas, fazer coisas eu digo aprender de diversas formas, eu não tenho um caminho exclusivo a seguir, eu não tenho apenas uma forma de fazer, então eu posso atingir meu objetivo, atingir o meu conhecimento de várias formas diferenciadas. Eu posso fazer a mesma coisa de várias formas diferenciadas (Sul 03).

O principal fator é a interdisciplinaridade. A Computação é o meio para todas as áreas do conhecimento. Nós, enquanto educadores de Computação, temos recursos que permitem percorrer diversas áreas do conhecimento. Por exemplo, é possível ensinar matemática e códigos binários ao mesmo tempo, devido a relação entre as áreas (Nordeste 04).

Para Nordeste 04, a área de Computação oferece recursos e ferramentas que podem promover a interdisciplinaridade, a fim de que os objetivos sejam alcançados.

A interdisciplinaridade, enquanto princípio mediador entre as diferentes disciplinas, não poderá jamais ser elemento de redução a um denominador comum, mas elemento teórico-metodológico da diferença e da criatividade. A interdisciplinaridade é o princípio da máxima exploração das potencialidades de cada ciência, da compreensão dos seus limites, mas, acima de tudo é o princípio da diversidade e da criatividade [Etges, 1993, p. 18].

Portanto, a interdisciplinaridade no ensino de Computação é uma forma de superar os problemas causados pela fragmentação, ou especialização do conhecimento computacional, pois a fragmentação fragiliza a produção do conhecimento. A interdisciplinaridade é muito fecunda para o trabalho colaborativo, no seio do qual a produção do conhecimento se dá no coletivo, o que torna essa produção mais forte do ponto de vista epistemológico.

\subsection{Contextualização}

A fim de ilustrar situações práticas de contextualização no ensino de Computação, atente-se para o que diz Wing (2006): 
Considere esses exemplos do dia a dia: quando sua filha vai para a escola pela manhã, ela coloca em sua mochila as coisas que precisará para utilizar durante o dia; isso é prefatching ${ }^{2}$ e caching $^{3}$. Quando seu filho perde suas luvas e você sugere que ele refaça seus passos; isso é backtracking ${ }^{4}$ (p. 34).

Ao contemplar tal ideia, é possível perceber que o Pensamento/raciocínio Computacional está inserido, faz parte do cotidiano das pessoas, nos vocabulários de diferentes idiomas, desse modo torna-se imprescindível que o ensino de Computação esteja relacionado ao uso do raciocínio computacional no dia a dia. Na concepção de Fourez (1998), "um modelo, um conceito, uma representação estão contextualizados quando são apresentados com seu contexto de invenção ou de uso pertinente" (p. 121).

Por meio dos trechos das narrativas dos entrevistados, constata-se que há no campo do $P C K$ dos professores de Computação uma predisposição para a contextualização do conteúdo disciplinar.

[...] ele [professor de Computação] deve ser preparado na verdade para conseguir compreender sempre qual é a metodologia mais adequada para uma dada situação sobre o ponto de vista cultural, sobre o ponto de vista geográfico, sobre o ponto de vista temporal (Nordeste 04 ).

[...] não adianta o professor ser muito bom na área da Computação e ele não conseguir ah... e ele não conseguir... transmitir esse conhecimento de maneira adequada para os seus estudantes. [...] trabalhar com projetos também é bem interessante, porque você consegue envolver os alunos em alguma coisa que seja do convívio diário deles (Sul 01).

Há indicativos nas falas dos egressos Nordeste 04 e Sul 01 de que no ensino de Computação faz-se necessário adequar os conteúdos ao contexto cultural, geográfico e temporal dos alunos. Porém, ressalta-se que o conceito de contextualização não deve ser reduzido apenas à ideia de formular atividades que contemplem a realidade imediata dos alunos. A contextualização se dá quando problematiza-se o conteúdo em outro contexto diferente [Ricardo, 2003].

Conforme estudos de Fourez (1998), os conceitos de contextualização e interdisciplinaridade estão de certo modo interligados, pois, para o autor, os meios que conduzem à contextualização naturalmente exigirão um exercício interdisciplinar por parte do professor.

\subsection{Mediação}

O conceito de mediação que será tomado para a análise, está embasado nos estudos de Vigotsky (1998) e Martins e Moser (2012).

De acordo com Vigotsky (1998), toda ação humana supõe uma mediação, para ele a aprendizagem ocorre através de uma mediação semiótica ou pela interação com o outro. Desse modo, o processo de aprendizagem é visto como uma ação mediada.

Conforme Martins e Moser (2012), os meios que favorecem a mediação compreendem tudo aquilo que o homem utiliza para ter acesso ao mundo, porém é importante ressaltar que os meios ou as ferramentas que constituem a mediação "não produzem o significado nem a aprendizagem" (p. 11).

\footnotetext{
2 Pré-busca eficiente, pré-resgate.

3 Memorização.

4 Backtracking é um algoritmo genérico que busca, por força bruta, soluções possíveis para problemas computacionais.
} 
Com o surgimento das tecnologias digitais, o potencial de mediação para a aprendizagem expandiu-se aumentando as possibilidades de aprendizagem.

Diante dessa situação, os professores de Computação reconhecem seu importante papel como mediadores e também compreendem que o ensino de Computação promove o uso de ferramentas potencializadoras da mediação para que ocorra a aprendizagem.

"Então eu me vejo como uma mediadora" (Sul 03).

"[...] por que aí, vem aquele famoso "ensinar a ensinar", no sentido de que o professor de Computação consiga fazer todo o acompanhamento do aluno, o processo de mediação na parte técnica" (Sul 02).

Eu acho que as melhores metodologias são metodologias dinâmicas e que envolvam trabalhos em grupo. [...]é bem importante você tentar usar essas estratégias de ensino com trabalhos em grupo, com ferramentas que possibilitem que eles interajam em um grupo (Sul 01).

O entrevistado Sul 01, indica que em sua prática ocorre a aprendizagem mediada através de trabalhos em grupo, ou por comunidades de prática. Essas atividades surtem maior efeito para o envolvimento da geração atual nas aulas.

Nesse modelo de ensino-aprendizagem, o professor coloca-se como o orientador do processo de construção do conhecimento, procurando despertar nos seus alunos a curiosidade e a inventividade que resulta na aprendizagem significativa. ${ }^{5}$

\subsection{Planejamento}

O conceito de planejamento é inerente à atividade de qualquer profissional do ensino, é o principal conceito da formação didática dos futuros professores. Para Libâneo (2016), a elaboração do planejamento de ensino é o encontro da didática básica, enquanto teoria do ensino generalizada, com as didáticas específicas ou disciplinares.

Sob esse prisma, compreende-se que o planejamento pedagógico deve ser desenvolvido de forma conectada com todos os demais conceitos elencados como categorias do $P C K$ dos professores de Computação.

Os relatos a seguir revelam que o planejamento, tanto no sentido de exercício da atividade docente, quanto como conceito presente na atividade computacional, está também no campo do conhecimento pedagógico do professor de Computação.

"Me formei para isso, para dar aulas, a gente planeja a aula e também estruturamos a avaliação de acordo com o que acontece na aula, então, nesse momento de fazer o planejamento da aula o curso ajudou muito" (Nordeste 2).

Então, é tranquilo, você vai lá, vê o plano de curso, vê as atividades que você tem que desenvolver, os conteúdos que você tem que desenvolver, e a partir daquilo você faz o teu planejamento. Você tem que ver o conteúdo que você vai desenvolver, você tem que dominar esse conteúdo, então tem que estudar, tem que visualizar todo este conteúdo, e fazer o plano da aula (Sul 03).

\footnotetext{
${ }^{5}$ Aprendizagem é dita significativa quando uma nova informação (conceito, ideia, proposição) adquire significados para o aprendiz através de uma espécie de ancoragem em aspectos relevantes da estrutura cognitiva preexistente do indivíduo, em conceitos, ideias, proposições já existentes em sua estrutura de conhecimentos (ou de significados) com determinado grau de clareza, estabilidade e diferenciação [Moreira, 1982].
} 
Observa-se, mediante os relatos, que ao longo da formação os egressos da Licenciatura em Computação foram preparados para a atividade docente de forma que construíram seu posicionamento pedagógico quanto ao ato de planejar. Pois a atividade de planejar requer um processo de pensar sobre o que estão fazendo e pensar sobre sua própria base de conhecimento [Mishra; Koehler, 2006].

Em meio a essa miríade de considerações, depreende-se que o $P C K$ dos professores de Computação, apresentado nesta pesquisa, representa de certo modo um construto que indica a base de conhecimentos através da qual os professores de Computação amparam-se pedagogicamente quando são confrontados com os desafios impostos pela/na prática do ensino.

Porém, acredita-se que o $P C K$ dos professores de Computação não se encerranos 7 (sete) atributos aqui apresentados, compreende-se que o estudo do $P C K$ de um professor é bastante complexo, devido, dentre outros aspectos, ao fato de se tratar de um conjunto de conhecimentos implícitos, que podem ser explicitados de diversas outras formas [Fernandez, 2011].

\section{CONCLUSÃO}

Ao longo de sua atividade profissional, os professores de Computação constroem uma base de conhecimentos pedagógicos que são gerados a partir da interseção entre os conhecimentos disciplinares que trazem da formação e os conhecimentos pedagógicos que também são adquiridos nos processos formativos e nas experiências. Essa interseção ocorre quando o professor precisa operacionalizar o ensino de Computação, então, são gerados os saberes da sabedoria da prática, quando o professor adapta os conhecimentos disciplinares e os conhecimentos pedagógicos, a fim de tornar o conteúdo "ensinável" e acessível aos alunos.

Logo, foi possível indicar 7 (sete) atributos que colaboram para ilustrar o Pedagogical Content Knowledge dos professores de Computação.

Os professores de Computação demonstram que sua base de Conhecimento de Conteúdo Pedagógico para o ensino de Computação é orientada pelos seguintes atributos: autonomia, transposição didática, contextualização, pensamento/raciocínio computacional, mediação, interdisciplinaridade, e planejamento.

$\mathrm{O}$ conjunto dos atributos que compõem a base do PCK do professor de Computação aqui apresentado revela que esse profissional traz em sua postura pedagógica marcas de um profissional contemporâneo que consegue perceber as novas demandas pedagógicas do ensino para a geração nativa digital [Prensky, 2001] que tem ao seu dispor tecnologias informacionais cada vez mais cedo, que lhes concedem acesso imediato em qualquer local a conhecimentos aos quais gerações passadas só teriam acesso ao chegar na universidade.

A educação computacional, com base no $P C K$ dos professores de Computação, deverá promover a autonomia desses sujeitos, a fim de que possam gerir todo o aparato tecnológico ao seu redor e não apenas confinarem-se à condição de consumidores passivos. Para isso, a exploração de sua capacidade de abstração, de raciocínio computacional deverá ser trabalhada através da transposição didática dos saberes científicos da Computação para a condição de saberes computacionais acessíveis ao educando. Esse processo é mediado pela contextualização de um planejamento para o ensino de Computação amparado em uma perspectiva interdisciplinar. 


\section{Referencias}

Bardin, L. (2016) Análise do Conteúdo. Tradução Luís Antero Reto. - São Paulo: Edições 70.

Bouchard, J. (2013) "Pedagogical Content Knowledge. Research Starters: Education (Online Edition)". Disponível em < http://ezl.periodicos.capes.gov.br/login?url=http://search.ebscohost.com $>$ Acesso em $08 / 08 / 2018$.

Chevallard, Y. (1998) "La transposición didáctica: del saber, al saber enseñado." $3^{\mathrm{a}}$ Edição. Argentina: Aique.

Etges, N. J. (1993) "Produção do conhecimento e interdisciplinaridade." Educação e Realidade. Porto Alegre, v. 18, n. 2, p. 73-82, jul/dez.

Fernandez, C. (2011). "PCK - Conhecimento Pedagógico do Conteúdo: perspectivas e possibilidades para a formação de professores.” In: Anais do VIII ENPEC Encontro Nacional de Pesquisa em Educação em Ciências, volume 1, Campinas, São Paulo. Disponível em< https://www.researchgate.net/publication/282330402_PCK__Conhecimento_Pedagogico_do_Conteudo perspectivas_e possibilidades_para a $\mathrm{f}$ ormacao_de professores> Acesso em Abril de 2018.

Fourez, G. (1998) Saber sobre nuestros saberes: un léxico epistemológico para la enseñanza. Buenos Aires: Ediciones Colihue.

Harris, J.; Mishra, P.; Koehler, M. (2009) “Teacher's technological Pedagogical Content Knowledge and learning activity types: curriculum-based technology integration Reframed."Journal of Research on Tehnology in Education. ISTE: Canadá. Disponível em www.iste.org Acesso em maio de 2017.

Hennessey, E. J. V., Mueller, J., Beckett, D. \& Fisher, P. A. (2017) "Hiding in Plain Sight: identifying computational thinking in the Ontario Elementary School curriculum." In: Journal of Curriculum and Teaching. V. 6, N. 1. April. Disponível em $<$ http://jet.sciedupress.com $>$ Acesso em setembro de 2018.

Libâneo, J. C. (2016) "A teoria do ensino para o desenvolvimento humano e o planejamento de ensino.” Educativa, Goiânia, v. 19, n. 2, p. 353-387, maio/ago. Disponível em $<$ http://seer.pucgoias.edu.br/index.php/educativa/article/view/5391/2954> Acesso em fevereiro de 2019.

Marcon, D. (2013) Conhecimento pedagógico do conteúdo: a integração dos conhecimentos do professor para viabilizar a aprendizagem dos alunos. - Caxias do Sul-RS: Educs.

Martins, O. B.; Moser, A. (2012) "Conceito de mediação em Vygotsky, Leontiev e Wertsch.” Revista Intersaberes. v. 7, n. 13, p. 8-28, jan-jun. Disponível em <

https://www.uninter.com/intersaberes/index.php/revista/article/viewFile/245/154> Acesso em fevereiro de 2019.

Mishra, P.; Koehler, M. J.(2006). "Technological Pedagogical Content Knowledge: a framework for teacher Knowledge." Teachers College Record. Columbia University, v. 108 , n. 6 , p. 1017-1054, june. 
Moreira, M. A.; Masini, E. A. F. S. (1992). "Aprendizagem significativa: a teoria de David Ausubel." São Paulo, Moraes.

Prensky, M. (2011). "Chronicle of Higher Education.” The Chronicle of Higher Education, V. 58, n. 13. Nov. Disponível em< ebscohost.ez356.periodicos.capes.gov.br> Acesso em dezembro de 2018.

Prensky, M. (2012). “Aprendizagem baseada em jogos digitais.” Tradução de Eric Yamagute. - São Paulo: Editora Senac São Paulo.

Ricardo, E. C. (2003) "A problematização e a contextualização no ensino das ciências: acerca das ideias de Paulo Freire e Gérard Fourez." Anais do IV Encontro Nacional de Pesquisa em Educação em Ciências. Bauru, SP. Disponível em < http://www.fep.if.usp.br/ profis/arquivos/ivenpec/Arquivos/Orais/ORAL019.pdf> Acesso em fevereiro de 2019.

Shulman, L. S. (1986) "Those who understand: knowledge growth in teaching." Educational Researcher, v. 15, n. 4, p. 4-14. Disponível em < http://www.fisica.uniud.it/URDF/masterDidSciUD/materiali/pdf/Shulman_1986.pdf $>$ Acesso em maio de 2017. . (2014) "Conhecimento e ensino: fundamentos para a nova reforma. Tradução de Leda Beck.” Cadernos Cenpec, São Paulo, v. 4, n. 2, p. 196-229, dez.

Teixeira, C. G.; Bastos, R. M. (2016) “Computação e convergência de disciplinas: nosso modo de trabalhar precisa dar conta da complexidade." Revista da Sociedade Brasileira de Computação. n. 31, v. 02, p. 21-25. Disponível em < http://www.sbc.org.br/images/flippingbook/computacaobrasil/computa_31/Comp_Br asil_02_2016.pdf $>$. Acesso em 01/2019.

Trocmé-Fabre, H. (2004) A árvore do saber-aprender: rumo a um referencial cognitivo. Tradução de Marly Segreto. São Paulo: TRYOM.

Vigotsky, L. S. (1998). A formação social da mente. 6. ed. Trad. José Cipolla Neto, Luis S. M. Barreto e Solange C. Afeche. São Paulo: M. Fontes.

Wing, J. (2006). "Computational Thinking." Communications of the ACM. v. 49, n.3, p. 33-35, New York. 